\title{
A Decade of Public Health Genomics in the United States: Centers for Disease Control and Prevention 1997-2007
}

\author{
M.J. Khoury S. Bowen L.A. Bradley R. Coates N.F. Dowling M. Gwinn \\ K. Kolor C.A. Moore J.St. Pierre R. Valdez P.W. Yoon \\ National Office of Public Health Genomics, Centers for Disease Control and Prevention, Atlanta, Ga., USA
}

\section{Key Words}

Epidemiology $\cdot$ Genetics $\cdot$ Genomics $\cdot$ Public health

\begin{abstract}
Since 1997, the Centers for Disease Control and Prevention (CDC) has collaborated with numerous partners to develop and chart the course of the multidisciplinary field of public health genomics in the USA and globally. During this period, CDC has developed major initiatives for the appropriate integration of genomics into public health research, policy and programs. In this paper, we review briefly the progress in public health genomics made over the past decade in the USA, including population research, the human genome epidemiology network (HuGENet ${ }^{\mathrm{TM}}$ ), the evaluation of genomic applications in practice and prevention (EGAPP), the family history public health initiative, and efforts in building the public health genomics capacity. We also outline a vision for public health genomics for the next decade.
\end{abstract}

Copyright $\odot 2008$ S. Karger AG, Basel

The findings and conclusions of this report are those of the authors and do not necessarily reflect the views of the Department of Health and Human Services.

\section{KARGER}

Fax +41613061234 E-Mail karger@karger.ch www.karger.com

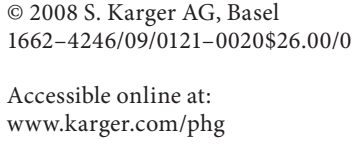

In 1997, the Centers for Disease Control and Prevention (CDC), the U.S. federal agency given primary responsibility for health protection and disease prevention, created the National Office of Public Health Genomics (NOPHG, initially named the Office of Genetics and Disease Prevention) to provide a public health response to the Human Genome Project and other advances in genome-based technologies [1]. For the past 10 years, CDC has collaborated with numerous partners including federal and state health agencies, public health schools, professional medical and allied health groups, academia, the private sector, and international groups to develop and chart the course of the multidisciplinary field of public health genomics in the USA and globally. During this period, CDC has developed major initiatives for the appropriate integration of genomics into public health research, policy, and programs. In this paper, we review briefly the progress in public health genomics made over the past decade in the United States and outline a vision for the second decade. This report will focus on activities initiated by the NOPHG. Other ongoing CDC genetic efforts such as in newborn screening, genetic testing quality assurance, and birth defects and developmental disabilities can be found on the CDC Genomics website [1]. 


\section{The Challenge of Public Health Genomics}

Public health genomics is 'a multidisciplinary field concerned with the effective and responsible translation of genome-based knowledge and technologies to improve population health' [2]. Public health genomics seeks to use population-based data on genetic variation and gene-environment interactions to develop, implement, and evaluate evidence-based tools for improving health and preventing disease. It also applies systematic evidence-based assessments of genomic applications in health practice and works to ensure the delivery of validated, useful genomic tools for the benefit of population health.

Public health genomics is now needed more than ever to address the opportunities provided by the Human Genome Project and the emergence of 'omic' disciplines, such as proteomics, nutrigenomics, and pharmacogenomics. Undoubtedly, scientific breakthroughs will help unravel the biological mechanisms underlying drug, nutritional, environmental, and lifestyle factors in the etiology and pathogenesis of numerous common diseases of public health significance. Many scientists are already seeing that these breakthroughs will lead to near-term health applications. Dr. Elias Zerhouni, Director of the National Institutes for Health (NIH), boldly predicted that 'comprehensive, genomics-based health care will become the norm, with individualized preventive medicine and early detection of illnesses' [3]. The recent introduction of the CYP450 test to help providers prescribe selective serotonin reuptake inhibitors (SSRIs) in the treatment of adults with depression has announced the new era of pharmacogenomics worldwide [4]. In 2007, after they published online the first complete sequence of an individual human being, Levy et al. [5] predicted that 'we have developed a framework that can serve as a model for the development of the emerging field of en masse personalized genomics'.

Nevertheless, health applications of genomic research so far remain focused on individually rare single gene disorders, which account for most of the 1,500 genetic tests currently available for practice or research use. Even with impressive advances in the basic sciences of gene discovery and characterization, reservations have been voiced about the potential benefits of medical applications of genomics; these reservations are based in part on the complex relationship between genetic variation and the environment with disease occurrence, as reflected in the modest associations between individual gene variants and disease outcomes, and the limited clinical validity and utility of using genetic information in the prediction of disease. Moreover, prematurely optimistic claims by researchers, the media, test developers, and commercial genomic enterprises may lead to unrealistic expectations among consumers and inappropriate use of genetic information. Also, an overemphasis on the genetics of human disease may divert attention from the importance of environmental exposures, social structure, and lifestyle factors [2].

In public health practice, skepticism about genomics runs high among some practitioners whose traditional domains are the control of infectious diseases, environmental exposures, and health promotion for chronic disease prevention. To some, genomics research is perceived as a low-yield investment, as well as an opportunity cost, undercutting social efforts to address environmental causes of ill health $[6,7]$. Some others envision public health applications of genomics only in terms of population screening and argue that this approach will remain limited to newborn screening programs [8]. Still others reject genomics research as an unwarranted extension of the individual risk paradigm [9], citing the distinction between prevention in populations and in high-risk persons set out by Geoffrey Rose some years ago [10]; however, Rose was careful to present these approaches as complementary rather than mutually exclusive [11].

We have argued that the integration of genomics into health care and disease prevention requires a strong medicine-public health partnership [11]. While it is acknowledged that healthcare is part of the public health system, in the United States public health and healthcare often operate in parallel spheres [11]. This 'schism' can be overcome in genomics using a population approach to a joint translational agenda that includes: (a) a focus on prevention - a traditional public health concern but now a promise of genomics in the realm of personalized medicine; (b) a population perspective which requires a large amount of population level data to validate gene discoveries for clinical and population level applications, especially given the modest associations between genetic factors and disease burden; (c) commitments to evidence-based knowledge synthesis and guideline development, especially with thousands of potential genomic applications emerging into practice; (d) emphasis on health services research and the surveillance of population health to evaluate health outcomes, costs and benefits in the 'real world'. A strong medicine-public health partnership in the genomics era is needed for the translation of genomics and other scientific discoveries for the benefit of population health. An example of such partnership is illustrated using hereditary hemochromatosis (table 1) [11]. 
We have also described in detail how medicine-public health partnership can cover the 4 phases of translation research in genomics [12]. Phase 1 (T1) research seeks to move a basic genome-based discovery into a candidate health application (e.g., genetic test/intervention). Phase 2 (T2) research assesses the value of a genomic application for health practice leading to the development of evidence-based guidelines. Phase 3 (T3) research attempts to move evidence-based guidelines into health practice, through delivery, dissemination, and diffusion research. Phase 4 (T4) research seeks to evaluate the 'real world' health outcomes of a genomic application in practice. Because the development of evidence-based guidelines is a moving target, the types of translation research can overlap and provide feedback loops to allow integration of new knowledge. Although it is difficult to quantify how much of genomics research is T1, we have estimated that no more than $3 \%$ of published research focuses on $\mathrm{T} 2$ and beyond [12]. Indeed, evidence-based guidelines and T3 and $\mathrm{T} 4$ research currently are rare (except in newborn screening). The types of public health research and evaluation needed for genomics translation are shown in table 2 .

\section{Major CDC Initiatives in Public Health Genomics}

The CDC has initiated a number of initiatives to close the widening gap between gene discoveries and population health benefits. These are shown in figure 1 and discussed briefly below.

\section{Population Health Research}

Here we highlight 2 examples of CDC-driven population health research.

Assessing the Genome Profile of the U.S. Population. Determination of the prevalence of genetic polymorphisms of public health importance in the U.S. population, and in subgroups of the population, is a critical first step in evaluating the genetic epidemiology of complex diseases. Such data would be an invaluable resource for (a) investigations into U.S. population genetics structure, and (b) calculations of population attributable fraction(s) of the burden of disease associated with genetic variation and gene-environment interaction. In addition, population-based data on allele and genotype prevalence would serve as a reference for researchers to be used in designing future association studies in population subgroups. In 2003, the CDC proposed to use DNA samples collected in the Third National Health and Nutrition Examina-

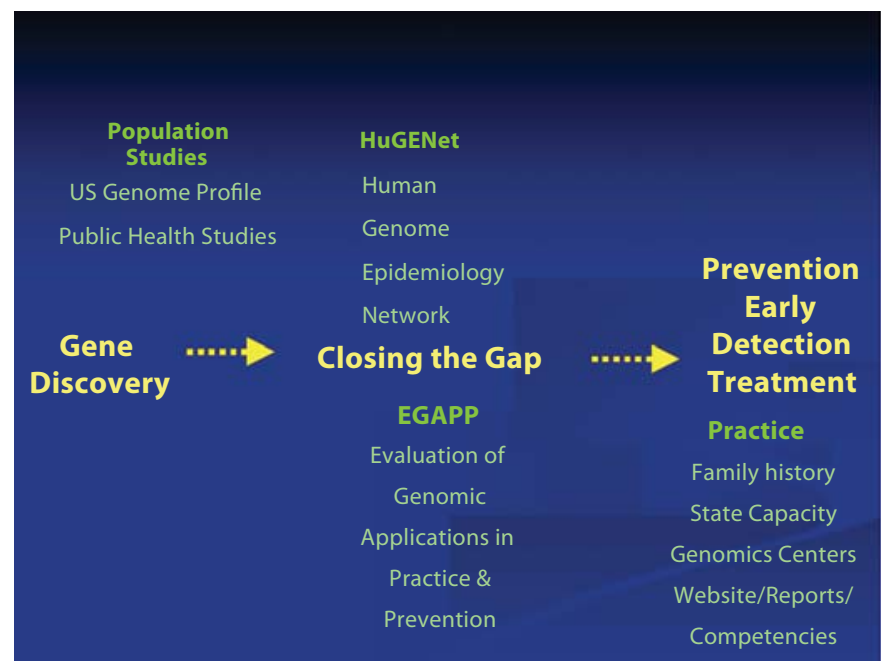

Fig. 1. Public health genomics at CDC: closing the gap between gene discovery and population health.

Table 1. Hereditary hemochromatosis ( $\mathrm{HH})$ : an example of medicine-public health partnership in the translation of a gene discovery into health practice (see reference [11] for details)

\begin{tabular}{ll}
\hline $\begin{array}{l}\text { Area of } \\
\text { collaboration }\end{array}$ & Description \\
\hline Prevention & $\begin{array}{l}\text { A joint CDC-NIH workshop was held shortly after } \\
\text { the HFE gene was discovered to discuss the preven- } \\
\text { tive benefits from screening for HFE mutations to } \\
\text { prevent complications of iron overload from HH. } \\
\text { This led to a research and practice agenda. }\end{array}$ \\
\hline $\begin{array}{l}\text { Public } \\
\text { health }\end{array}$ & $\begin{array}{l}\text { Mutation prevalence study in U.S. population; } \\
\text { studies of burden of hospitalization and deaths; } \\
\text { large cohort study to assess penetrance and natu- } \\
\text { ral history. }\end{array}$ \\
\hline $\begin{array}{l}\text { Knowledge } \\
\text { integration }\end{array}$ & $\begin{array}{l}\text { 2006 evidence-based knowledge synthesis and rec- } \\
\text { ommendations against population testing by the }\end{array}$ \\
$\begin{array}{l}\text { USPSTF (U.S. Preventive Services Task Force), } \\
\text { based on best available data. }\end{array}$ \\
$\begin{array}{l}\text { Health } \\
\text { services } \\
\text { research }\end{array}$ & $\begin{array}{l}\text { Active ongoing CDC provider education campaign } \\
\text { to encourage early detection and case finding; eval- } \\
\text { uation is in progress. }\end{array}$ \\
\hline
\end{tabular}

tion survey (NHANES) III, one of a series of representative population-based samples of the U.S. population with over-sampling of certain ethnic/racial minority groups. In 2007, CDC and NCI (National Cancer Institute) collaborators completed the genotyping of the first 90 variants in 50 genes of public health significance. A 
Table 2. Types of translation research involving a population approach and multiple scientific disciplines (see reference [12] for details)

\begin{tabular}{ll}
\hline $\begin{array}{l}\text { Human genome } \\
\text { epidemiology }\end{array}$ & $\begin{array}{l}\text { Research on prevalence of genetic risk factors, gene-disease associations, and gene- } \\
\text { gene and gene-environment interactions in human populations to quantify contribu- } \\
\text { tion of genetic factors to human diseases and magnitude of risks. }\end{array}$ \\
\hline $\begin{array}{l}\text { Genetic test evaluation } \\
\text { (ACCE components) }\end{array}$ & $\begin{array}{l}\text { A: Analytic validity. Research to measure the ability to accurately and reliably measure } \\
\text { the genotype of interest. The } 4 \text { main elements of analytic validity include analytic } \\
\text { sensitivity (or the analytic detection rate), analytic specificity (or 1 - the analytic false- } \\
\text { positive rate), laboratory quality control, and assay robustness. }\end{array}$ \\
\hline
\end{tabular}

C: Clinical validity. Research to measure the test's ability to detect or predict the associated disorder (phenotype).

C: Clinical utility. Research to define the risks and benefits associated with a test's introduction into practice. Specifically, clinical utility focuses on the health outcomes (both positive and negative) associated with testing.

E: Ethical, legal, and social issues (some view this component as part of clinical utility). Research to assess concerns specific to genetic information, such as implications for relatives of the person undergoing testing, the possibility of insurance discrimination, and stigmatization based on genotype.

Clinical trials Phase I. Research on a new drug or treatment in a small group of people (20-80) for the first time to evaluate its safety, determine a safe dosage range, and identify side effects.

Phase II. The study drug or treatment is given to a larger group of people (100-300) to see if it is effective and to further evaluate its safety.

Phase III. The study drug or treatment is given to large groups of people $(1,000-3,000)$ to confirm its effectiveness, monitor side effects, compare it to commonly used treatments, and collect information that will allow the drug or treatment to be used safely.

Phase IV. The post-marketing studies delineate additional information including the drug's risks, benefits, and optimal use.

Research from evidence guidelines to practice
Dissemination research. Systematic study of how the targeted distribution of information and intervention materials to a specific health audience can be successfully executed so that increased spread of knowledge about the evidence-based interventions achieves greater use and impact of the intervention.

Implementation research. Systematic study on how a specific set of activities and designed strategies is used to successfully integrate an evidence-based intervention within specific settings (e.g., primary care clinic, community center, school).

Diffusion research. Systematic study of the factors necessary for successful adoption by stakeholders and the targeted population of an evidence-based intervention that results in widespread use and specifically includes the uptake of new practices or the penetration of broad-scale recommendations through dissemination and implementation efforts, marketing, laws and regulations, systems research, and policies.

Health impact research Outcomes research. Research that describes, interprets, and predicts the impact of various influences, especially (but not exclusively) interventions on 'final' endpoints that matter to decision makers. Decision makers may include patients, families, individuals at risk, providers, private and public payers, and so forth. 
manuscript describing the frequency of various alleles and genotypes is in press [13]. Also, statistical analysis of approximately 35 genotype-phenotype correlation studies is in progress with multiple published findings anticipated in 2008.

In 2007, CDC began the Beyond Gene Discovery (BGD) initiative, a public-private partnership and collaboration that will use a whole-genome approach (genotyping more than 1 million SNPs and copy number variants) to assess the prevalence of genetic polymorphisms in several NHANES surveys. When finalized, the initiative will provide the first population-based assessment of genomic variation for the U.S. population and its various subgroups. Furthermore, the initiative will establish an important database for analysis of genotype-phenotype correlations and gene-environment interactions using the thousands of phenotypic and environmental variables already collected in these surveys. Assessing the genetic associations with phenotypic measures that reflect intermediate stages along disease pathways (e.g., fasting blood glucose, body mass index) will enhance our understanding of environmental determinants of these diseases and gene-environment interactions $[14,15]$. Completion of this project will also enhance the value of many ongoing genome-wide association studies, helping to assess the public health impact of their newly discovered genes for common diseases.

Integrating Genomics into Public Health Investigations. $\mathrm{CDC}$ and other public health agencies conduct public health investigations of infectious diseases, environmental exposures, and chronic diseases of children and adults. These investigations improve the public's health by diagnosing, studying, and controlling diseases in communities. Collecting and analyzing human genomic data in public health investigations has the potential to enhance our ability to understand population variation in disease occurrence, characterize genetic susceptibility to environmental exposures, and refine public health interventions (e.g., vaccinations, exposure reduction, and health promotion). Also, over the past several years, NOPHG made available seed funding for more than a dozen innovative projects that integrate genomics into public health research and programs [16].

\section{The Human Genome Epidemiology Network $\left(\mathrm{HuGENet} \mathrm{T}^{\mathrm{TM}}\right)$}

In 1998, CDC established the Human Genome Epidemiology Network (HuGENet, http://www.cdc.gov/genomics/hugenet/default.htm) [17]. The goal of HuGENet is to help translate findings from genetic research into opportunities for preventive medicine and public health by advancing the synthesis, interpretation, and dissemination of population-based data on human genetic variation in health and disease. HuGENet has continued to grow as an open collaboration of researchers and organizations from around the world. During the last 5 years, in addition to CDC, 3 additional HuGENet coordinating centers were developed in the United Kingdom, Canada, and Greece [17]. In 2005, HuGENet launched the 'Network of Networks', an informal collaboration among existing research networks and consortia dedicated to the study of genetic factors in common diseases, such as cancer, heart disease, and osteoporosis [18]. Key activities of HuGENet include:

HuGENet Website. Established in 2000, HuGENet's free online resource includes a curated, weekly summary of newly published scientific articles on human genome epidemiology, a searchable database, case studies for training, and information on HuGE workshops and publications.

HuGE Reviews. These peer-reviewed, systematic reviews of gene-disease associations are published in partnership with 10 scientific journals. HuGE reviews typically point to gaps in existing epidemiologic and clinical knowledge, thus stimulating further research to bring genomic data to fruition in the context of improving the public's health.

HuGE Published Literature Database. Systematic collection of curated and relevant publications cited in PubMed began in October 2000. The database, which is updated weekly, is accessible on the Internet. Users can search the database by gene, health outcome, or environmental factor. Key information about each study is presented, along with a direct link to PubMed's abstract of the article. As of February 6, 2008, this searchable online database indexes more than 32,000 research studies, referencing more than 3,200 genes and 2,000 health outcomes/diseases. It includes more than $700 \mathrm{HuGE}$ reviews and meta-analyses of gene-disease associations.

HuGE Navigator. In July 2007, NOPHG launched the beta version of the HuGE Navigator (www.hugenavigator.net), a suite of online applications that mine PubMed to populate the HuGE Published Literature database, identify candidate genes, search for investigators with a particular research focus, and produce summaries of knowledge.

HuGENet Meetings and Workshops. Since 2001, 10 international meetings and workshops have focused on methods for evaluating, synthesizing and interpreting population-based data on genetic variation, gene-disease 
association, and gene-gene and gene-environment interactions. Each of these meetings has produced one or more peer-reviewed publications [e.g., 18].

HuGENet Network of Networks. A meeting in 2005 convened members of approximately 30 research networks, ranging from funded consortia to informal collaborating groups. Selected networks are currently piloting approaches to pooled data analysis and knowledge synthesis.

HuGENet Road Map. Published in January 2006, the road map outlines an approach to building the knowledge base on human genome epidemiology [19].

Strengthening the Reporting of Genetic Associations (STREGA). A workshop held in Canada in July 2006 engaged epidemiologists, geneticists, and journal editors in developing guidance for reporting research results in ways that promote knowledge synthesis [20].

Grading the Evidence for Genetic Associations. A workshop held in Venice in 2006 produced interim guidelines for the cumulative assessment of genetic associations [21].

\section{Evaluation of Genomic Applications in Practice and}

Prevention (EGAPP) Initiative

In 2004, CDC started the Evaluation of Genomic Applications in Practice and Prevention (EGAPP) initiative [22]. The main goal of EGAPP is to establish and test a systematic, evidence-based process for evaluating genetic tests and other applications of genomic technology that are in transition from research to clinical and public health practice. EGAPP has integrated existing recommendations and guidance on the implementation of genetic tests from professional organizations and advisory committees, task forces (e.g., U.S. Preventive Services Task Force, CDC's Task Force on Community Preventive Services), and international health technology assessments groups. EGAPP activities are focused around the independent, non-federal Working Group established in 2005. The roles of this multidisciplinary panel include optimizing methods and processes for evidence review to deal with complex and rapidly emerging technologies, identifying, prioritizing, and selecting topics, participating on technical expert panels that guide conduct of evidence reports, and developing recommendations for clinicians based on the evidence.

In 2007, 4 CDC-funded evidence reports were completed for the EGAPP Working Group by evidence-based practice centers (EPCs), through an interagency agreement with the Agency for Healthcare Research and Quality (AHRQ): (1) Genomic tests for detection and man- agement of ovarian cancer (www.ahrq.gov/clinic/tp/ genovctp.htm). (2) Testing for CYP450 polymorphisms in adults with non-psychotic depression treated with SSRIs (www.ahrq.gov/clinic/tp/cyp450tp.htm). (3) Hereditary nonpolyposis colorectal cancer: diagnostic strategies and their implications (http://www.ahrq.gov/clinic/ tp/hnpcctp.htm). (4) Impact of gene expression profiling tests on breast cancer outcomes (http://www.ahrq.gov/ clinic/tp/brcgenetp.htm).

Another non-EPC report on 'UGT1A1 genotyping and morbidity and mortality in patients with metastatic colorectal cancer treated with irinotecan', and a supplemental report 'DNA testing strategies aimed at reducing morbidity and mortality from Lynch syndrome', are in press.

Based on consideration of the availability and quality of evidence, and clinical and social contextual issues, the Working Group develops recommendations that summarize current knowledge, provide guidance on appropriate use, and define key gaps and needed research. In 2007, the first in a series of EGAPP Working Group recommendation statements on CYP450 testing in patients with depression treated with SSRIs was published [23]. Other reports are forthcoming in 2008.

\section{Integrating Genomics into Practice}

Since 1998, CDC has initiated a number of activities to integrate genomics into clinical and public health practice. The following is a brief summary of the major initiatives.

Family History Public Health Initiative. Recognizing the potential of family history for disease prevention and health promotion, CDC started the family history public health initiative in $2002[24,25]$. The purpose of this initiative is to ensure that family history is recognized as an important risk factor for common chronic diseases such as cancer, diabetes, and heart disease, and to promote its use in programs aimed at reducing the burden of these diseases in the U.S. population. Activities of this initiative include studies to assess the validity and utility of using family health history as a public health strategy; collaborating with the AHRQ to evaluate the validity and utility of family history tools; collaborations with federal, state and local public health agencies, universities, and private and not-for-profit organizations to develop and implement campaigns to increase public awareness about the public health importance of family history and to improve and facilitate the use of family history; as well as the development and dissemination of family history resources and tools through the CDC website, printed pub- 
lications, news media, conferences, meetings, workshops, and other venues.

A main objective of the initiative was to conduct an extensive review of existing family history tools and to develop criteria for the development of a new tool to assess risks for common chronic diseases (Family Healthware $^{\mathrm{TM}}$ ). This was accomplished by a multidisciplinary working group of experts in clinical genetics, behavioral science, health communication, preventive medicine, and epidemiology from the CDC, NIH, and other federal agencies, state public health programs, academia, and the health care community. The work group developed the following criteria for determining which diseases should be initially included in the family history tool: (1) substantial public health burden, (2) a clear case definition, (3) high awareness of disease status among relatives, (4) accurate reports by relatives, (5) family history found to be an established risk factor, (6) population prevalence of family history as a risk factor can be estimated, (7) effective interventions exist for primary and secondary prevention, and (8) different recommendations according to familial risk level may be possible. The working group selected 6 diseases (coronary heart disease, stroke, diabetes, and colorectal, breast, and ovarian cancer), and worked with a software development company to develop Family Healthware.

In 2005, the first research version of Family Healthware was completed. This web-based tool provides users with a familial risk assessment and a 'prevention plan' containing personalized recommendations for lifestyle changes and screening recommendations. The tool collects data from the users on (1) health behaviors (e.g., smoking and exercise), (2) screening tests (e.g., blood cholesterol and mammography), and (3) disease history of first- and second-degree relatives. A first set of algorithms assesses the familial risk for each disease. A second set of algorithms uses the familial risk combined with self-reported data on health behaviors and screening results to generate personalized prevention messages.

In 2005, CDC awarded funding to research groups at the University of Michigan School of Medicine, Evanston Northwestern Healthcare Research Institute, and Case Western Reserve University School of Medicine to evaluate the clinical utility of Family Healthware. Researchers recruited patients using a network of primary care practices to determine if prevention messages that are personalized based on familial risk can motivate people at risk to change their lifestyle or screening behaviors within 6 months of using Family Healthware. Data collection was completed in 2007 and the study findings will be published in 2008.

Building Public Health Genomics Capacity. In 2001, CDC published genomics competencies for the public health workforce [26]. Since 2002, CDC has funded Centers for Genomics and Public Health within schools of public health at the universities of North Carolina, Michigan, and Washington to provide expertise in translating genomic information into useable public health knowledge, to provide technical assistance to state and community public health agencies, and to integrate genomics into programs and practice [27]. Since 2003, CDC has supported genomics programs in 4 state health departments (Michigan, Minnesota, Oregon, and Utah) to integrate genomics knowledge (e.g., genetic risk factors) and tools (e.g., family history assessments) into chronic disease prevention programs and core public health functions [28]. Details of activities of states and schools of public health are described elsewhere [27, 28].

Communication and Education. Communication and educational strategies developed by CDC have targeted a broad range of internal and external audiences, including health care providers, public health practitioners, genomic researchers and practitioners, health care payers/purchasers, policy makers, and the general public. The communication strategy aims to encourage the integration of genomics into research, policy, and practice by developing and disseminating credible resources in public health genomics. Principal activities and products include: (1) the CDC public health genomics website which has more than 2,000 main pages of genomics information and resources and approximately 4,000 pages of presentations and interactive material; (2) a weekly online publication called Genomics \& Health Weekly Update, which reaches more than 6,000 subscribers worldwide; (3) CDC conferences, meetings, workshops, and seminars; (4) media interviews; (5) presentations and exhibit booths at public health events; (6) publications; (7) campaigns; (8) a public inquiry mailbox. In addition, the CDC has organized approximately 100 conferences, workshops, meetings, and seminars, involving partners from across CDC and collaborators for NOPHG initiatives. A striking new development in genomics is the advent of personal genome profile testing marketed directly to consumers. The premature use of these research tools in practice can lead to confusion of the general public and providers. CDC has spent a considerable effort in surveillance, evaluation, communication, and education around this area [29-31].

So what has been the population impact of these initiatives? Since the field is so young, it is difficult to measure 
how these initiatives have actually improved health at the population level. Nevertheless, there are several process indicators we can point to for potential impact. The first is the elevation of the role of population sciences and policy to the translation of genomics into health practice. Until recently, public health was thought to involve genetics only in the context of newborn screening. Now, the population perspective is increasingly represented in discussions on genomics in the USA (e.g., American Public Health Association Genomics Forum) and internationally [2]. The second is the validation of the role of evidence-based guidelines and policies in the appropriate use of genetic information. The EGAPP initiative has achieved a national and international measure of validation via the integrating concepts of genetic test evaluation in policy making and health technology assessments in several enterprises in Europe and North America. The third is the recognition of the importance of family history in health and disease beyond traditional genetic diseases. For example, the U.S. Surgeon General's campaign on family history awareness (http://www.hhs.gov/familyhistory/) has put this topic in the forefront of public health activities in the USA (e.g., addition of family history to several state health department chronic disease programs). Finally, international collaborations have expanded considerably over the past few years, partly as a result of CDC's efforts in connecting public health genomics worldwide both from academic institutions as well as government organizations (e.g., GRAPHint [2] and HuGENet [17]). In looking back over the first decade, having launched the public health genomics movement from a government public health agency has given the enterprise the credibility and visibility to impact public health issues that are facing the U.S. population. Government efforts have worked hand-in-hand with academic public health to integrate genomics into public health curricula and provide technical assistance to public health agencies in the use of genomics in disease prevention and health promotion efforts.

\section{Vision for the Second Decade}

The CDC vision for public health genomics in the USA in the next decade is to accelerate the evaluation and appropriate integration of new genomic knowledge and technologies into public health goals and actions. During the past 2 years, CDC has developed new goals for achieving greater health impact in the U.S. These goals are framed in the context of life stages, places, preparedness, and global health. Progress toward this vision will be accomplished in 2 phases. During the next 5 years, CDC plans to accelerate research and development of new information and tools for use by the public and the health care community. Specific approaches and products will include a human genome profile of the U.S. population, family history tools, genetic test evaluations, and dissemination of translational materials to the public and providers. CDC will fund intramural and extramural research on genomics and population health. During the following 5 years (phase 2), we envision a phased approach for integrating genomic information into public health programs that promote health and prevent disease. When evidence-based recommendations are developed, NOPHG will work with CDC programs to integrate them into public health guidance and programs implemented by CDC and its partners in the public health and clinical communities.

Here, we highlight a few initiatives that will be prominent in the next 10 years of public health genomics in addition to the ones described above.

\section{Accelerate Translation Research and Surveillance}

Through an extramural research funding announcement [32], CDC will continue to develop its portfolio for translation research and surveillance activities that will advance knowledge about the validity, utility, utilization, and population health impact of genomic tests and family history for improving health and preventing disease in well-defined populations or practice settings. The objective is to address key issues along the translation continuum, from (1) the initial development and evaluation of candidate genomic applications, to (2) a thorough evaluation of the genomic applications and development of evidence-based clinical practice guidelines for the use those applications, to (3) the dissemination and implementation of recommended applications in clinical and public health practice, to (4) the evaluation of the extent and fidelity with which recommended applications are implemented in community settings and the effect of implementation on population health.

\section{Sustainable EGAPP Process}

To adapt EGAPP to meet the growing challenges of evidence-based synthesis and information dissemination, CDC plans to evolve the EGAPP Working Group to enhance partnerships and collaborations with similar efforts around the country and globally. One goal is to get EGAPP products to be more timely yet authoritative by enhancing interactions with other groups and de- 
veloping and disseminating methods for such synthesis through one or more EGAPP knowledge synthesis centers. Through the translation research and surveillance research cooperative agreement discussed above, we plan to form a network of investigators (GAPPNet) to meet regularly to share methods and findings and to identify gaps suggesting additional research and surveillance activities. This network will advance our knowledge and dissemination of genomic applications for population health.

\section{Genomics for Early Disease Detection and}

Intervention Initiative (GEDDI)

CDC will work with many partners to develop and evaluate genomic applications that use clinical and genomic information, such as familial risk assessment, early recognition of signs and symptoms, and genetic testing to promote the prevention and early detection of both traditional genetic disorders and common diseases. For many years, integration of genomic applications into clinical practice has been focused on genetic testing for individually rare single gene disorders. More recently, we are seeing the introduction of genomic applications for common chronic diseases, e.g., by using genetic markers in early identification of cancer, or targeting therapies based on genotype that optimize response and avoid adverse drug reactions. We can expect increasingly rapid development of new genetic tests - including those that test multiple genetic markers concurrently using microarray technologies (multiplex testing) - that will be used to help refine diagnoses, improve risk prediction, and target therapies for both traditional genetic disorders as well as common chronic diseases. In the meantime, genomic applications already being used in clinical medicine can be evaluated at the population level for assessing disease risk, influencing the early detection of disease, and providing guidance for disease prevention or management. These applications including familial risk assessment, recognition of signs and symptoms, and genetic testing - when used as public health strategies - could contribute to improve population health.

Family history is an important tool for identifying individuals and families with genetic susceptibility to common chronic diseases such as coronary heart disease, stroke, diabetes, and most cancers, as well as rare single gene disorders like cystic fibrosis, sickle cell anemia, and hereditary forms of breast and colorectal cancer. As an integral part of primary care and preventive medicine, familial risk assessment has the potential to identify people at risk of disease, those with subclinical disease, and those who may already be affected but are undiagnosed. There are many single gene disorders across the life span that could benefit from early disease detection and interventions through a closer partnership between medicine and public health. Many affected persons with genetic diseases such as hereditary hemochromatosis [33], familial hypercholesterolemia [34], and primary immune deficiency disorders [35], for example, are either missed by the health care system or not diagnosed early enough for effective and appropriate interventions to work. Thus, valuable opportunities for preventing disease and disability are lost. A public health approach employing public and provider education about symptom recognition, surveillance strategies, screening, and referral to appropriate services could be used to enhance existing health care practice, leading to earlier diagnosis of these disorders.

\section{Concluding Remarks}

Public health genomics in the USA has developed in response to the opportunities and challenges of ongoing advances in genomics and related technologies. While the promise of genomics for health practice is still far away, we have to pave the foundation for the appropriate applications of technologies for the benefit of population health. A public health approach is needed to ensure that all segments of the population will benefit from validated technologies while inappropriate or premature use of these technologies is minimized. In addition, public health research is needed to be conducted to assess the contributions of genomes and their interactions with modifiable factors to the burden of disease and disability. Finally, continuous synthesis and integration of the evolving knowledge is needed to develop evidence-based guidelines for the use of genomic information and technologies and uncover gaps in knowledge that require additional basic and translational research.

\footnotetext{
References $\quad 1$ Centers for Disease Control and Prevention. The National Office of Public Health Genomics. http://www.cdc.gov/genomics/ (accessed online January 2, 2008).

2 Burke W, Khoury MJ, Stewart A, Zimmern RL, Bellagio Group: The path from genomebased research to population health: development of an international public health genomics network. Genet Med 2006;8: 451-458.
} 
3 Zerhouni E: NIH Press release: NIH seeks input on proposed repository for genetic information. August 30, 2006. http://www.nih. gov/news/pr/aug2006/od-30.htm (accessed online September 1, 2006).

4 Amplichip homepage. http://www.amplichip.us/ (accessed online January 2, 2008).

5 Levy S, Sutton G, Ng PC, Feuk L, Halpern AL, Walenz BP, Axelrod N, Huang J, Kirkness EF, Denisov G, Lin Y, MacDonald JR, Pang AW, Shago M, Stockwell TB, Tsiamouri A, Bafna V, Bansal V, Kravitz SA, Busam DA, Beeson KY, McIntosh TC, Remington KA, Abril JF, Gill J, Borman J, Rogers YH, Frazier ME, Scherer SW, Strausberg RL, Venter JC: The diploid genome sequence of an individual human. PLoS Biol 2007;5:e254.

6 Chaufan C: How much can a large population study on genes, environments, their interactions and common diseases contribute to the health of the American people? Soc Sci Med 2007;65:1730-1741.

7 Buchanan AV, Weiss KM, Fullerton SM: Dissecting complex disease: the quest for the philosopher's stone? Int J Epidemiol 2006;35: 562-571.

-8 Holtzman NA: What role for public health in genetics and vice versa? Community Genet 2006;9:8-20.

9 Rockhill B: Theorizing about causes at the individual level while estimating effects at the population level: implications for prevention. Epidemiology 2005;16:124-129.

10 Rose G: Sick individuals and sick populations. Int J Epidemiol 1985;14:32-38.

-11 Khoury MJ, Gwinn M, Burke W, Bowen MS, Zimmern RL: Will genomics widen or help heal the schism between medicine and public health? Am J Prev Med 2007;33:310-317.

12 Khoury MJ, Gwinn M, Yoon PW, Dowling N, Moore CA, Bradley C: The continuum of translation research in genomic medicine: how can we accelerate the appropriate integration of human genome discoveries into health care and disease prevention? Genet Med 2007;9:665-674.

13 Chang $\mathrm{MH}$, Lindegren ML, Moore C, Khoury MJ: Prevalence in genetic variants of public health significance in the United States. Am J Epidemiol, submitted.

14 Davey Smith G, Ebrahim S: 'Mendelian randomization': can genetic epidemiology contribute to understanding environmental determinants of disease? Int J Epidemiol 2003; 32:1-22.

15 Khoury MJ, Davis RL, Gwinn M, Lindegren ML, Yoon PW: Do we need genomic research for the prevention of common diseases with environmental causes? Am J Epidemiol 2005;161:799-805.
16 CDC National Office of Public Health Genomics. http://www.cdc.gov/genomics/activities/fund2006.htm (accessed online January 2, 2008).

17 The Human Genome Epidemiology Network (HuGENet). http://www.cdc.gov/genomics/hugenet/default.htm (accessed online January 2, 2008)

18 Ioannidis JP, Bernstein J, Boffetta P, Danesh J, Dolan S, Hartge P, Hunter D, Inskip P, Jarvelin MR, Little J, Maraganore DM, Bishop JA, O'Brien TR, Petersen G, Riboli E Seminara D, Taioli E, Uitterlinden AG, Vineis P, Winn DM, Salanti G, Higgins JP, Khoury MJ: A network of investigator networks in human genome epidemiology. Am J Epidemiol 2005;162:302-304.

19 Ioannidis JP, Gwinn M, Little J, Higgins JP, Bernstein JL, Boffetta P, Bondy M, Bray MS Brenchley PE, Buffler PA, Casas JP, Chokkalingam A, Danesh J, Smith GD, Dolan S, Duncan R, Gruis NA, Hartge P, Hashibe M, Hunter DJ, Jarvelin MR, Malmer B, Maraganore DM, Newton-Bishop JA, O'Brien TR, Petersen G, Riboli E, Salanti G, Seminara D, Smeeth L, Taioli E, Timpson N, Uitterlinden AG, Vineis P, Wareham N, Winn DM, Zimmern R, Khoury MJ: A road map for efficient and reliable human genome epidemiology. Nat Genet 2006;38:3-5.

20 HuGENet workshop. Strengthening the reporting of genetic associations (STREGA) Manuscript in preparation. Details on workshop available at http://www.cdc.gov/genomics/hugenet/strega.htm.

21 Ioannidis JP, Boffetta P, Little J, O’Brien TR, Uitterlinden AG, Vineis P, Balding DJ, Chokkalingam A, Dolan SM, Flanders WD, Higgins JP, McCarthy MI, McDermott DH, Page GP, Rebbeck TR, Seminara D, Khoury MJ: Assessment of cumulative evidence on genetic associations: interim guidelines. Int Epidemiol 2008;37:120-132.

22 Evaluation of Genomic Applications in Practice and Prevention (EGAPP). http://www. egappreviews.org/ (accessed online January 2, 2008)

23 Evaluation of Genomic Applications in Practice and Prevention (EGAPP) Working Group. Recommendations from the EGAPP Working Group: Testing for cytochrome P450 polymorphisms in adults with nonpsychotic depression treated with selective serotonin reuptake inhibitors. Genet Med 2007; 9:819-825.
24 CDC National Office of Public Health Genomics: Family history public health initiative. http://www.cdc.gov/genomics/activities/famhx.htm (accessed online January 2, 2008)

25 Yoon PW, Scheuner MT, Khoury MJ: Research priorities for evaluating family history in the prevention of common chronic diseases. Am J Prev Med 2003;24:128-135.

26 CDC National Office of Public Health Genomics: Genomics competencies for the public health workforce. http://www.cdc. gov/genomics/training/competencies/default.htm (accessed online January 2, 2008).

27 CDC National Office of Public Health Genomics: Centers for genomics and public health. http://www.cdc.gov/genomics/activities/fund2005.htm (accessed online January 2, 2008).

28 CDC National Office of Public Health Genomics: Developing state capacity for integrating genomics into chronic disease programs. http://www.cdc.gov/genomics/activities/ogdp/2005/chap10.htm (accessed online January 2, 2008).

29 Goddard KAB, Moore C, Ottman D, Bradley L, Khoury MJ: Awareness and use of direct-to-consumer nutrigenomic tests, United States, 2006. Genet Med 2007;9:510-517.

30 Jannssens AC, Gwinn M, Bradley LA, Oostra BA, van Dujin CM, Khoury MJ: A critical appraisal of the scientific basis of commercial genomic profiles used to assess health risks and personalize health interventions. Am J Hum Genet 2008;82:593-595.

- 31 Hunter D, Khoury MJ, Drazen J: Letting the genome out of the bottle - will we get our wish? New Engl J Med 2008;358:105-107.

32 CDC National Office of Public Health Genomics: Genomics applications in practice and prevention translation research. Funding announcement. http://www07.grants. gov/search/search.do;jsessionid=HLHJnKs TGktmyTnSm 9B1vv4W3VVQR1T2Td 2FDTVR3nHZbXyFyyHt!-1797286335?opp Id $=16029 \&$ flag $2006=$ true $\&$ mode $=$ VIEW (accessed online January 2, 2008).

33 Waalen J, Beutler E: Hereditary hemochromatosis. Screening and management. Curr Hematol Rep 2006;5:34-40.

34 MED PED (Make Early Diagnosis Prevent Early Deaths) website. http://www.medped. org/ (accessed online January 2, 2008).

35 Modell Foundation: 10 warning signs for primary immune deficiency disorders. http://www.info4pi.org/patienttopatient/index.cfm?section=patienttopatient $\&$ content =warningsigns (accessed online January 2, 2008). 